ARTICLES

\title{
Gender Is a Natural Kind with a Historical Essence*
}

\section{Theodore Bach}

Traditional debate on the metaphysics of gender has been a contrast of essentialist and social-constructionist positions. The standard reaction to this opposition is that neither position alone has the theoretical resources required to satisfy an equitable politics. This has caused a number of theorists to suggest ways in which gender is unified on the basis of social rather than biological characteristics but is "real" or "objective" nonetheless-a position I term "social objectivism'. This essay begins by making explicit the motivations for, and central assumptions of, social objectivism. I then propose that gender is better understood as a real kind with a historical essence, analogous to the biologist's claim that species are historical entities. I argue that this proposal achieves a better solution to the problems that motivate social objectivism. Moreover, the account is consistent with a postpositivist understanding of the classificatory practices employed within the natural and social sciences.

\section{INTRODUCTION: A DILEMMA IN FEMINIST THEORY}

Is gender a real kind in nature? Historically, feminists have had reason to answer both "yes" and "no." In her influential 1988 essay "Cultural Feminisim versus Post-structuralism: The Identity Crisis in Feminist Theory," Linda Alcoff explains: "The cultural feminist response to Simone de Beauvoir's question, 'Are there women?' is to answer yes

* Many thanks to Diana Meyers, Dan Ryder, David Slutsky, Ruth Millikan, Tom Bontly, and Laurie Shrage for helpful discussions and comments on earlier versions of this article. I am also grateful to two anonymous referees as well as the editors from Ethics. A previous version of this article was given at the 2009 Eastern meeting of the American Philosophical Association, where I received many helpful comments and questions from audience members.

Ethics 122 (January 2012): 231-272

(C) 2012 by The University of Chicago. All rights reserved. 0014-1704/2012/12202-0001\$10.00 
and to define women by their activities and attributes in the present culture. The post-structuralist response is to answer no and attack the category and the concept of woman through problematizing subjectivity."

Cultural feminists describe women as a real kind but claim that the essence of this kind has been obscured and devalued by androcentric cultural practices. Poststructuralists, on the other hand, claim that the very idea of a coherent category "women" is a myth that functions in the service of patriarchy. Alcoff continues: "Each response has serious limitations, and it is becoming increasingly obvious that transcending these limitations while retaining the theoretical framework from which they emerge is impossible." ${ }^{2}$ Poststructuralists are limited by their denial of the category woman and therefore the inability politically to represent women. Cultural feminists are limited by their exclusion of prima facie women who fail to satisfy enough properties of the posited feminine essence.

This trade-off between cultural feminism and poststructuralism is an instance of a general dilemma for feminist theory that has yet to be satisfactorily resolved: either accept the normative consequences of articulating real gender kinds or accept the normative consequences of rejecting real gender kinds. The goal of this essay is to sketch a solution to this dilemma. Like several other researchers investigating the status of human kinds, ${ }^{3}$ I draw from principles recently employed within naturalistic epistemology and ontology. But unlike current approaches to the naturalization of human kinds I claim that gender kinds are natural kinds with a historical essence and also that members of a gender kind possess a common teleological function. I argue for the ironic conclusion that this appeal to essence and function achieves a better solution to the theoretical and political problems that motivate anti-essentialist accounts of gender.

Here is how I will proceed. In the next section, I explain how realism about gender leads to either the "Representation Problem" or the "Commonality Problem." In Section III, I explicate a current solution to these problems that I term 'social objectivism'. Section IV introduces the ontology of historical kinds, and Section V argues that gender kinds are historical kinds. In Section VI, I argue that a historical essentialist construal of gender provides the best solution to

1. Linda Alcoff, "Cultural Feminism versus Post-structuralism: The Identity Crisis in Feminist Theory," Sions: Journal of Women in Culture and Societv 13 (1988): 405-36, 407.

2. Ibid., 407.

3. See, e.g., Richard Boyd, "Homeostasis, Species, and Higher Taxa," in Species: New Interdisciplinary Essays, ed. R. A. Wilson (Cambridge, MA: MIT Press, 1999), 141-85; Ron Mallon, "Social Construction, Social Roles, and Stability," in Socializing Metaphysics: The Nature of Social Reality, ed. Frederick F. Schmitt (Lanham, MD: Rowman \& Littlefield, 2003), 327-54. 
the Commonality and Representation Problems. Section VII concludes.

\section{THE REPRESENTATION AND COMMONALITY PROBLEMS}

One way to be a realist about a category $K$ is to claim that members of $K$ share an intrinsic property $P$ in virtue of which they belong to $K$. Property $P$ is then the intrinsic or "Aristotelian" essence of $K$. One way to schematize this view is the following:

An individual $Q$ belongs to kind $K$ if and only if $Q$ possesses properties $\{P i \ldots P n\}$ and $(a)\{P i \ldots P n\}$ are necessary and sufficient for being a $K,(b)\{P i \ldots P n\}$ are identical to or supervene on intrinsic properties of $Q,(c)\{P i \ldots P n\}$ are immutable ("fixed"), and $(d)$ the relationship between $\{P i \ldots P n\}$ and a set of characteristic/salient properties of $K$ is causal rather than conceptual.

This schema offers conditions for kind essence rather than individual essence. Members of the kind gold essentially have the atomic number of 79. Yet certain individuals survive the loss of this property (a gold-plated chalice), while other individuals presumably do not (a solid gold ring). ${ }^{4}$

A maligned tradition of philosophical and scientific theorizing, commonly termed 'biological essentialism' or 'biologism', ascribes an intrinsic essence to gender categories in a way that is analogous to gold. The causally relevant internal properties on this view are primary sexual characteristics. For example:

An individual $Q$ belongs to the kind woman if and only if $Q$ possesses XX chromosomes and female reproductive organs. These properties $(a)$ are individually necessary and jointly sufficient for being a woman, $(b)$ supervene on, or are identical with, Q's occurrent physiology, $(c)$ consist in the same thing in all times and places, and $(d)$ are causally rather than conceptually related to $Q$ 's salient, gendered behavior.

Biological essentialism has historically been placed in the service of misogynist agenda. It has, for good reasons, been subject to much philosophical and scientific criticism. The view is most commonly at-

4. For further discussion of the distinction between individual and kind essence, see Samir Okasha, "Darwinian Metaphysics: Species and the Question of Essentialism," Synthese 131 (2002): 191-213; and Stephen Schwartz, "The Essence of Essence," Australasian Journal of Philosophy 87 (2009): 609-23. For a discussion of how various views on gender conflate this distinction, see Natalie Stoljar, "Essence, Identity, and the Concept of a Woman," Philosophical Topics 23 (1995): 261-92. 
tacked on the grounds that it is empirically false and that it explains the social status of women as inevitable, necessary, and therefore justified.

One response to biological essentialism is to deny that there are real ontological kinds that correspond to the categories "women" and "men." On this view, the only unity that exists for members of a gender category is a conceptual or linguistic unity. Alcoff's poststructuralist feminists, who include Kristeva, Foucault, Derrida, and Martin, each reject that gender categories refer to mind-independent kinds. Several political advantages motivate this position: misogynist principles are not recycled in the act of defining women, critical genealogies reveal sources of oppression, and marginalized groups of women are not excluded. The result is "free play of a plurality of differences unhampered by any predetermined gender identity." But most feminists agree that these advantages come at a cost. The idea that there is a single group of women united in political struggle is made incoherent through a nominalist commitment to the mere conceptual or linguistic status of women. Whose autonomy is denied by androcentric norms? Whose identity is irreducible to primary and secondary sexual characteristics? Call this the Representation Problem: if there is no real group "women," then it is incoherent to make moral claims and advance political policies on behalf of women. ${ }^{6}$

In order to avoid both the misogynistic implications of biological

5. Alcoff, "Cultural Feminism versus Post-structuralism," 418.

6. See also ibid.; Iris Marion Young, "Gender as Seriality: Thinking about Women as a Social Collective," Signs 19 (1994): 713-38; Stoljar, "Concept of a Woman”; Sally Haslanger, "Gender and Race: (What) Are They? (What) Do We Want Them to Be?" Noûs 34 (2000): 3155; Alison Stone, "Essentialism and Anti-essentialism in Feminist Philosophy," Lournal of Moral Philosophy 1 (2004): 135-53.

Several considerations make the realist/nonrealist division more complicated than can be explained in these brief remarks. Anticipating the explanatory approach to natural (or real) kinds put forward in Sec. IV, I assume that nonrealism about gender requires the acceptance of at least two theses. First, that no current or future explanatory schemes require reference to the shared properties of gender kind members. Second, that any current or future explanatory scheme that purports a referential relation to gender is either vacuous, or, to use Kitcher's phrase, "objectively wrong-headed" (Phillip Kitcher, "Species," Philosophy of Science 51 [1984]: 308-33, 330). The gender scheme of Aristotle and Galen, according to which differences in the body temperatures of males and females causally explain certain developmental and behavioral gender differences, is objectively wrong-headed (see Nancy Tuana, The Less Noble Sex: Scientific, Religious, and Philosophical Conceptions of Woman's Nature [Bloomington: Indiana University Press, 1993], 18-22). Further muddying these waters is the semantic externalist thesis that our (gender) concepts might refer to natural kinds even if their associated descriptions are false. For discussions on the interaction between semantic and ontological issues with respect to social kinds, see Sally Haslanger, "What Good Are Our Intuitions? Philosophical Analysis and Social Kinds," Proceedings of the Aristotelian Society 80, suppl. (2006): 89-118; and Ron Mallon, "'Race': Normative, Not Metaphysical or Semantic," Ethics 116 (2006): 525-51. 
essentialism and the political implications of the Representation Problem, many feminist scholars have claimed that the category women is defined by an essential social property: women are real, but their unity is socially rather than biologically caused. For example, Nancy Chodorow holds that the difference between men and women is, to put it simply, a difference between a masculine sense of self (separate from the world) and a feminine sense of self (connected to the world). ${ }^{7}$ This view distinguishes real psychological categories but insists that these categories arise from contingent social divisions of labor rather than from physiological differences. One can interpret Catharine Mackinnon as advancing a structurally similar theory of gender. According to MacKinnon, individuals are women in virtue of their experience of sexual subordination, where subordination is expressed by contingent social institutions such as pornography.

A considerable amount of feminist scholarship describes how social definitions of gender such as the above lead to a distinct set of problems. Two problems-the "commonality" (or "diversity") and "normativity" problems-figure prominently in this literature. While biological essentialist views generate insidious versions of these problems, the universalism implicit in feminist, social definitions of gender invoke them as well. I think that there are in fact four versions of these problems, not always kept distinct, which I will group under the common heading the Commonality Problems:

1. Inseparability: Gender is not a feature that exists and develops independently of other (social) features such as race, class, and religion.

2. Universality: There is simply no feature that all women of all times and places have in common.

3. Immutability: By defining women according to property $P$ it follows that (i) the elimination of $P$ entails the elimination of women, (ii) if an individual possesses $P$ at time 1 and loses $P$ at time 2, then that individual is no longer a woman.

4. Normativity: Defining women according to an essential property privileges those who possess this property, or who possess more of it, and marginalizes those who do not possess this property, or who do not possess enough of it.

Critics describe how Chodorow's definition of gender encounters each of these problems: ${ }^{8}$ they point out that gendered personality does not develop independently of race, class, and religion (the in-

7. See Nancy Chodorow, Reproducing Mothering (Berkeley: University of California Press, 1978), 169.

8. See, e.g. Elizabeth Spelman, Inessential Woman (Boston: Beacon, 1988). 
separability problem), that not all women satisfy the description of a feminine sense of self (the universality problem), that gender groups would continue to exist even if new modes of socialization were to emerge (the immutability problem), and that the identification between feminine sense of self and womanhood marginalizes those women who do not possess a feminine personality (the normativity problem).

\section{SOCIAL OBJECTIVISM}

A current response to both the Representation and Commonality Problems is a position I term 'social objectivism'. Social objectivism employs two dialectical moves designed to address the feminist dilemma. First, it defines women according to a suitably abstract relational property. This produces an answer to the Commonality Problems while avoiding the universalism implicit in extant biological and social definitions of gender. Second, it employs an ontologically thin notion of "objectivity," thereby providing an answer to the Representation Problem. More formally, a socially objective kind is one for which

(a) the defining property is the result of contingent cultural practices,

(b) the defining property is a relational rather than intrinsic property, and

(c) the defining property is "objective" rather than nominal or essential.

Sally Haslanger has argued for a definition of gender along these lines, offering the following: ${ }^{9}$

$\mathrm{S}$ is a woman iff (if and only if) $\mathrm{S}$ is systematically subordinated along some dimension (economic, political, legal, social, etc.), and $\mathrm{S}$ is "marked" as a target for this treatment by observed or imagined bodily features presumed to be evidence of a female's biological role in reproduction.

$\mathrm{S}$ is a man iff $\mathrm{S}$ is systematically privileged along some dimension (economic, political, legal, social, etc.), and S is "marked" as a target for this treatment by observed or imagined bodily features presumed to be evidence of a male's biological role in reproduction.

These definitions satisfy the first condition of social objectivism because social norms and institutions could have been other than they are, in which case males and females need not have been systematically privileged and subordinated. The definitions satisfy the second

9. Haslanger, "Gender and Race," 50. 
condition because privilege and subordination are relational properties that require social relata.

Haslanger states that her account is able to provide a solution to several of the Commonality Problems. Her view does not assume inseparability because it "allows that the substantive import of gender varies from individual to individual within a culture depending on how the meaning of sex interacts with other socially salient characteristics (e.g., race, class, sexuality, etc.)." ${ }^{10}$ With respect to universality, she writes: "To be a Chinese woman of the 1790's, a Brazilian woman of the 1890's, or an American woman of the 1990's may involve very different social relations, and very different kinds of oppression. Yet on the analysis suggested, these groups count as women insofar as their subordinate positions are marked and justified by reference to (female) sex." ${ }^{11}$

The idea seems to be this: by defining women according to an abstract relational property, one can capitalize on the fact that relational category members differ greatly with respect to their intrinsic, perceptual, and other social features. Consider the relational category gift. Something is a gift if it plays a specific relational role within a schema of gift-giving. As long as a token object satisfies this role, there is no limit on what other properties it might exemplify. A gift, then, can be realized by just about any object: car, diamond, lamp, frozen steak, naming a star after someone, and so on. Similarly, individuals of various races, classes, and interests can realize the social role "subordinated based on observed or imagined sex." The only prima facie women who fall outside Haslanger's definition are those who are not subordinated on the basis of perceived or imagined sex. Haslanger is willing to accept this weakened version of the commonality argument, partly because she's not convinced there are such women. ${ }^{12}$

Haslanger uses a somewhat different strategy to tackle the normativity and immutability problems. She concedes that her account may be "implicitly offering a normative ideal of women." ${ }^{13}$ She also concedes a version of immutability by advocating for an egalitarian gender system and therefore the elimination of men and women. Yet Haslanger maintains that the theoretical categories "men" and "women" play a central role in defining normative agenda and that the definitions she provides, while perhaps excluding and marginalizing certain individuals, are important for a positive feminist politics. In other words, the very social issues that motivate discussion of the

10. Ibid., 39.

11. Ibid.

12. Ibid., 46.

13. Ibid. 
Commonality Problems may be best served by an account that, to some small degree, commits minor versions of these problems. ${ }^{14}$

But in what sense does this nonessentialist concept of gender track a real structure of reality as opposed to a conventional aspect of our categorizing? That is, how does social objectivism avoid the Representation Problem? In a couple of recent papers, Haslanger defends the reality of social kinds through the notion of an objective type-a concept she borrows from Armstrong. ${ }^{15}$ While an objective type does not have an essence, and for this reason is not a "natural kind" on Haslanger's terminology, "the notion of objective type needed is not too mysterious: a set of objects is more an objective type by virtue of the degree of unity amongst its members beyond a random or gerrymandered set." ${ }^{16}$ Haslanger's method of determining if a set of objects has unity is to investigate if, and to what degree, they are in some sense similar. In order for the type to be objective, then, the axis of similarity must be objective as opposed to merely conceptual. As such, objective types represent very weak ontological unities. Indeed, Haslanger notes that the "items on her desk" constitute an objective type because they share a property and that property exists objectively rather than nominally. In the case of gender kinds, the objective similarity is the social role of subordination or privileging. As I develop the point in Sections V and VI, it is possible, and politically desirable, to provide a stronger ontological characterization of the genders men and women according to which they are natural kinds with explanatory essences. ${ }^{17}$

While a number of feminist scholars working on the question of gender may not use Haslanger's exact terminology, it is clear that they are relying on the metaphysical picture that Haslanger has made explicit and which reconciles the Representation and Commonality Problems. This is the group that I am terming 'social objectivists'. Consider Alcoff's theory that the concept "woman" should be under-

14. Haslanger writes: "The important issue is not whether a particular account 'marginalizes' some individuals, but whether its doing so is in conflict with the feminist values that motivate the inquiry. And as far as I can tell, not focusing our theoretical efforts on understanding the position of oppressed females would pose just such a conflict" (ibid.). 1989).

15. See David Armstrong, Universals: An Opinionated Introduction (Boulder, CO: Westview,

16. Haslanger, "Philosophical Analysis and Social Kinds," 109-10.

17. It is not always clear when Haslanger is involved in what she calls a "descriptive" project — where one attempts to discover and taxonomize objective types—or an "ameliorative" (Haslanger, "Philosophical Analysis and Social Kinds") /"analytic" (Haslanger, "Gender and Race") project-where the goal is to describe categories that are politically and epistemically useful. For my purposes it does not matter. In Sec. V, I argue that a historical essentialist account of gender is preferable for the descriptive project, and in Sec. VI I argue that the historical account is preferable for the ameliorative/analytic project. 
stood through the notion of positionality. A woman's position is determined by a set of cultural practices and expectations that are organized around the perception of an individual's possible relationship to biological reproduction (e.g., giving birth). The reality of gender derives from the objectivity of this social context, and it follows that women constitute an objective type. Yet, an individual's position also serves as a point of political departure and gendered subjectivity. Because "the identity of a woman is the product of her own interpretation and reconstruction of her history, as mediated through the cultural discursive text to which she has access," ${ }^{18}$ the type women does not enforce a common subjective experience or style. Iris Marion Young's account that women constitute a social series is also an example of social objectivism. A series is a "collective whose members are unified passively by the relation their actions have to material objects and practico-inert histories." ${ }^{19}$ Women are a series, unified through their individual relations to the same (objective) set of androcentric institutions, artifacts, and norms. Yet, individual members of the series can differ greatly in other respects.

The theories of Haslanger, Alcoff, and Young each exemplify the social objectivist schema: there is an objective similarity that is relational, based on contingent cultural processes, and which binds members into a type (purchasing representation), but the objective similarity does not preclude other objective dissimilarities that are constitutive of the target group (purchasing diversity). Social objectivism is an attractive position because it appears to occupy the only logical space where the Representation and Commonality Problems are jointly solved and where the intuition that gender has a core "social" rather than "natural" dimension is preserved. In the following section, I show how the possibility of historical essences undermines this claim.

\section{NATURAL KINDS WITH HISTORICAL ESSENCES}

Several feminist authors have emphasized that most analytic philosophers no longer accept a strict identification between essentialism and Aristotelian, intrinsic essentialism. ${ }^{20}$ At the same time, theorists working more directly in the philosophy of science have urged that recent naturalistic approaches to essentialism have important implications

18. Alcoff, "Cultural Feminism versus Post-structuralism," 434.

19. Young, "Gender as Seriality," 727-28.

20. See, e.g., Diana Fuss, Essentially Speaking (New York: Routledge, 1989); Susan Babbit, Impossible Dreams (Boulder, CO: Westview, 1996); Linda Alcoff, Visible Identities: Race, Gender, and the Self (Oxford: Oxford University Press, 2005); Haslanger, "Philosophical Analysis and Social Kinds." 
for our understanding of social kinds. ${ }^{21}$ But the full import of these insights for a theory of gender has not been realized. In particular, the notion of a historical essence has not been adequately applied to the ontology of gender. Modeling men and women as historical kinds, I now argue, achieves the strongest response to both the Representation Problem and the Commonality Problem.

\section{A. The Explanatory Approach to Natural Kinds}

In order for inductive practices to be successful, there must be stable correlations of properties that repeat or co-occur throughout nature or a domain of nature. According to the explanatory approach to natural kinds, natural kinds are the mind-independent ontological structures that support successful inductive practice..$^{22}$ In other words, a natural kind is a stable set of correlated properties that can be fruitfully studied. To use a stock example, instances of water reliably exhibit a similar boiling point and potential to quench thirst. Scientists can observe these properties in a few samples of water and, on account of water's status as a natural kind, accurately generalize these properties to unencountered samples. On the other hand, if a theoretical category fails to yield reliable predictions and explanations, then this is evidence that it is not tracking a natural kind. The "superlunary" category of Aristotelian physics groups together all of the objects outside of the moon's orbit. As Griffiths points out, "nothing follows from the

21. See, e.g., Boyd, "Homeostasis, Species, and Higher Taxa"; Ruth Millikan, On Clear and Confused Ideas (Cambridge: Cambridge University Press, 2000); Mallon, "Social Construction, Social Roles, and Stability"; Crawford Elder, Real Natures and Familiar Objects (Cambridge, MA: MIT Press, 2004).

22. The following philosophers adopt some version of the explanatory approach to natural kinds: W. V. O. Quine, Ontological Relativity and Other Essays (New York: Columbia University Press, 1969); Kitcher, "Species"; Richard Boyd, "Realism, Anti-Foundationalism, and the Enthusiasm for Natural Kinds," Philosophical Studies 61 (1991): 127-48; John Dupré, The Disorder of Things. Metaphysical Foundations of the Disunity of Science (Cambridge, MA: Harvard University Press, 1993); Hillary Kornblith, Inductive Inference and Its Natural Ground (Cambridge, MA: MIT Press, 1993); Paul E. Griffiths, "Squaring the Circle: Natural Kinds with Historical Essences," in Wilson, Species: New Interdisciplinary Essays (1999), 209-28; Millikan, Clear and Confused; Joseph Laporte, Natural Kinds and Conceptual Change (New York: Cambridge University Press, 2004). For specific formulations, see Boyd's "accommodation thesis" and Millikan's theory of "substances" (Millikan, Clear and Confused, chap. 2).

Two important issues for this theory of kinds are not discussed here. The first concerns how much of a contribution a theoretical category must make to inductive practices in order to reference a natural kind. On Griffiths's view reference to kind members must at least result in above-chance predictions. A related issue concerns whether the legitimacy of explanatory schema can be extended outside of the academic sciences (see Dupré, The Disorder of Things; Boyd, "Homeostasis, Species, and Higher Taxa"; Millikan, Clear and Confused; and Laporte, Natural Kinds and Conceptual Change). Boyd and Millikan suggest a continuum of epistemic legitimacy, with some folk inferential practices (e.g., folk psychology) found at the limit of kindtracking explanatory schemes. 
fact that an object is superlunary other than the fact that it is superlunary and trivial transformations of this (e.g., it is not sublunary). There is no epistemic pay-off to be had by using this category." ${ }^{23}$ The objects outside of the moon's orbit are an objective type, but according to current scientific theory, they are not a natural kind.

The explanatory approach frees the notion of kind essence from its traditional and problematic implications. The essence of a natural kind on this view is the source that organizes, or accounts for, reliable property correlations. ${ }^{24}$ It is the select property, or set of properties, that explains why one instance of the kind is nonaccidentally like another instance of the kind. In the case of water, the source of property correlation is the microstructure $\mathrm{H} 2 \mathrm{O}$ : the reason that two samples of water share a similar boiling point is their intrinsic microstructure. ${ }^{25}$ However, sources of property correlation are not always intrinsic features of kind members. Any source of property correlation that supports induction functions as the essence of a theoretical category, or at least plays the theoretical role assigned to "essence" on Aristotelian and positivist models. ${ }^{26}$ It is now widely accepted that kinds often manifest property regularity on the basis of relational properties. While generalizations that range over such kinds are more exception-prone, they nevertheless make important explanatory contributions. For example, the economic category money yields important generalizations (e.g., about inflation) that, while not exceptionless, are not available on explanatory schemes that restrict classifications on the basis of intrinsic properties.

Boyd and Mallon employ Boyd's "homeostatic property cluster" (HPC) version of the explanatory approach to natural kinds in order to argue that social roles are natural kinds. ${ }^{27}$ On the HPC view, natural kinds are stable clusters of properties, and in many cases there is a "homeostatic mechanism" that causes and sustains the property clustering. Applying this account to social roles, Boyd and Mallon claim

23. Paul E. Griffiths, What Emotions Reallv Are: The Problem of Psvchological Categories (Chicago: University of Chicago Press, 1997), 171.

24. See Boyd, "Realism and Anti-Foundationalism"; Kornblith, Inductive Inference, Griffiths, "Squaring the Circle"; Millikan, Clear and Confused; and Dan Ryder, "SINBAD Neurosemantics: A Theory of Mental Representation," Mind and Lanquage 19 (2004): 211-40.

25. On the other hand, "surface-water," which includes both samples with an $\mathrm{H} 2 \mathrm{O}$ microstructure and samples with an XYZ microstructure, is not a natural kind because likeness between XYZ-water and H2O-water are accidental. Similar considerations apply to jade, which includes the minerals jadeite and nephrite. For a discussion, see Crawford Elder, "Higher and Lower Essential Natures," American Philosophical Quarterly 31 (1993): 255-65.

26. See, esp., Griffiths, "Squaring the Circle." The helpful phrase "source of correlation" is from Ryder, "SINBAD Neurosemantics."

27. Boyd, "Homeostasis, Species, and Higher Taxa"; Mallon, "Social Construction, Social Roles, and Stability." 
that social role occupants exhibit imperfect similarity and that this similarity is the result of a relationally described social property. So, for instance, Mallon argues that a social role consists in a set of labeling and conceptual practices and that a social role is a homeostatic mechanism that causally sustains a cluster of characteristic properties for its occupants. Applied to gender, the rough idea appears to be that there is a set of cultural practices and beliefs about women (and men) that constitutes a "social role" and which (probabilistically) causes individual women to exhibit characteristic gendered behavior and traits. ${ }^{28}$

The HPC approach to social kinds makes progress toward reconciling the Commonality and Representation Problems. It permits diversity across social role occupants because occupants need only imperfectly realize a social kind's characteristic property cluster. The account also employs a principled view of ontological classification that generalizes to the natural sciences. Yet, I will claim that the explanatory approach to natural kinds makes available a characterization of social kinds that is importantly distinct from the Boyd-Mallon view and that has an important advantage in its capacity to address the Commonality Problems. I turn now to this alternative.

\section{B. Historical Essentialism}

Two samples of gold share likenesses due to nonhistorical facts about their microstructure. This is an example of what Ruth Millikan calls an "eternal kind" - a natural kind for which members' spatiotemporal locations play no role in the explanation of their similarities. Reacting to developments in the study of biological species and categories, Millikan and several other researchers now emphasize the role that historical properties can play in supporting inductive practices. ${ }^{29}$ According to this view, historical facts about genetic replication and past selective pressures explain why the members of a species share a phenotypic profile. Millikan calls natural kinds whose members are similar to one another on account of their historical relations to one

28. Neither Boyd nor Mallon offer a theory of the ontology of gender, yet both appeal to examples of gender in order to establish their HPC analysis of social kinds. I further discuss the prospects for a HPC analysis of gender in Sec. VI.A.

29. See Ruth Millikan, "Historical Kinds and the Special Sciences," Philosophical Studies 95 (1999): 45-65, and Clear and Confused; Griffiths, Emotions, and "Squaring the Circle"; Crawford Elder, "On the Reality of Medium-Sized Objects," Philosophical Studies 83 (1996): 191-211, "A Different Kind of Natural Kind," Australasian Journal of Philosophy 73 (1995): 516-31, and Real Natures. 
another historical kinds. ${ }^{30}$ In contrast to eternal kinds, there is no natural law by which the essence of a historical kind causes or accounts for the surface features of the kind. For example, there is no nomological connection between the essential historical relations that unify members of the kind Homo sapiens and any particular phenotype. All that is required to be a member of a historical kind is to possess the historical essence of that kind.

Let's get clear on the essence of a historical kind. Millikan sets out some general conditions for historical kind membership:

Why members of a [historical] kind might be caused to be like one another are, first, that something akin to reproduction or copying has been going on, all the various members having been produced from one another or from the same models and/or, second, that the various members have been produced by, in, or in response to, the very same ongoing historical environment, for example, in response to the presence of members of other ongoing historical kinds. A third and ubiquitous causal factor often supporting the first is that some "function" is served by members of the kind, where function is understood roughly in the biological sense. . . . It is typical for these various reasons to be combined. ${ }^{31}$

The central relation that unites kind members and explains their likenesses is replication, or reproduction. If $B$ is copied from $A$, then $A$ and $B$ are alike because $B$ is copied from $A$. Direct replication occurs when tokens are directly copied from one another, as happens when a new genetic segment is copied from an old genetic segment. Indirect replication, or "reproduction," occurs when tokens are produced from a historical model or blueprint whose function is to produce members of that kind. For example, contemporary Rodin sculptures form a historical kind if they are produced from a token mold that is designed to reproduce a type of Rodin sculpture. Or biological devices such as Homo sapiens' anterior cruciate ligament form a his-

30. For similar views, see Griffiths's discussion of natural kinds with historical essences ("Squaring the Circle"), and Elder's theory of copied kinds ("Medium-Sized Objects," "Different Kind of Natural Kind," Real Natures). While there are important and interesting differences between these authors, each agree that historical properties are in some sense essential to a certain kind of real kind. For an attempt to revise Millikan's view, see David Slutsky, "Confusion and Dependence in Uses of History," Synthese, published online October 1, 2010, http:// dx.doi.org/10.1007/s11229-010-9785-4.

31. Millikan, Clear and Confused, 20-21. 
torical kind if they are produced from the "instructions" encoded in a segment of the human genome. ${ }^{32}$

When we examine replicative and reproductive processes in their natural settings, we observe a common interdependence with the other two conditions mentioned in Millikan's passage-function and co-existing historical kinds. Items replicated from lineages that resulted from selective processes possess a teleological function. According to etiological theories of function, a particular trait $T$ is selected for replication, over and against historical alternatives, because of a past favorable effect that $T$ caused for ancestors that possessed $T$. Once selected, $T$ has the function of causing this effect. ${ }^{33}$ For example, human hearts are reproduced from ancestral hearts because ancestral hearts, more so than historical alternatives, had the favorable effect of pumping human blood. "Pumping blood" is thus the teleological function of hearts, and we can say of a token heart that was reproduced from ancestral hearts that it is "supposed to" pump blood. Due to a variety of factors, and in particular infidelity in the genetic copying process, token hearts may fail to pump blood. Yet they are still hearts because they have the right historical relation to other hearts.

As this familiar story helps indicate, it is in reference to a historical context that includes co-existing and co-evolved items that we explain an item's teleological function. The function of a heart is relative to the cardiovascular system, a system that is composed of other biological devices such as capillaries and red blood cells with distinct teleological functions. This overall system was a candidate for selection insofar as its parts achieved a certain stability, and the system was selected for because it, more so than historical alternatives, produced a fitness-enhancing effect. It is somewhat unfortunate, or at

32. See the discussion of "reproductively established families" in chap. 1 of Ruth Millikan, Language, Thought, and Other Biological Categories (Cambridge, MA: MIT Press, 1984), for an example of a more technical and detailed account of replication and reproduction. For the remainder of the essay, I will use the terms 'replication' and 'reproduction' interchangeably. When I need to specifically discuss reproduction, I will make the distinction explicit.

33. See, e.g., Ruth Millikan, White Queen Psychology and Other Essays for Alice (Cambridge, MA: MIT Press, 1993), chap. 2. Etiological explanations of natural normativity are common in the philosophy of science, but they are not universally accepted. For discussion, see two edited volumes: David Buller, ed., Function, Selection, and Design (Albany: State University of New York Press, 1998); and Andrew Ariew, Robert Cummins, and Mark Perlman, eds., Functions: New Essays in the Philosophy of Psychology and Biology (Oxford: Oxford University Press, 2002). See Paul Sheldon Davies, Norms of Nature: Naturalism and the Nature of Functions (Cambridge, MA: MIT Press, 2004), chap. 4, and "The Nature of Natural Norms: Why Selected Functions Are Systemic Capacity Functions," Noûs 34 (2000): 85-107, for some specific challenges to etiological explanations of natural normativity. Etiological functions are a subtype of teleological functions, but I will be using the terms 'etiological' and 'teleological' interchangeably for the remainder of this article. 
least misleading, that "Cummins functions," which specify the function of a part relative to a complex supersystem, have been portrayed as theoretical rivals to teleological functions. Certainly the classifications are not co-extensive: some Cummins functions are not teleological (parts of a complex system that were not selected for, e.g., spandrels), and some teleological functions are not Cummins functions (selected-for traits that are not contributing to a supersystem, e.g., a diseased heart). But several authors have made clear that most teleological functions were selected for because they performed a Cummins function; ${ }^{34}$ as a matter of empirical fact, teleological functions and Cummins functions tend to nonaccidentally coincide. A bloodpumping, human heart is an example.

My discussion of natural kinds with historical essences, or "historical kinds," will focus on items that were selected for replication on account of some contribution they made to the stability and overall effect of a more general, selected-for system. In other words, I will focus on historical kinds for which the teleological function is also a Cummins function. This strategy has the additional benefit of unifying and codifying Millikan's three conditions for historical kind membership. Here is a summary of some important facts about these historical kinds:

1. The essential property of a historical kind, possession of which confers kind membership to an individual, is participation in a lineage.

2. This property defines kind essence rather than individual essence.

3. In order to exemplify this relational property an individual must be a replication or reproduction of ancestors from this lineage.

4. Replication and reproduction are ontogenetic processes. Reproduction is an ontogenetic process caused by mechanisms that, on account of their history, have the function of producing historical kind members.

5. While historical kind members tend to be like one another in various ways and on account of their history, nonhistorical similarities are not necessary for kind membership.

6. An individual that is reproduced from a historical lineage that resulted from selective processes possesses a teleological function.

34. See, e.g., Kitcher, "Species"; Paul E. Griffiths, "Functions Analysis and Proper Functions," British Journal for the Philosophy of Science 44 (1993): 409-22; David Buller, "Etiological Theories of Functions: A Geographical Survey," Bioloov and Philosophy 4 (1998): 505-27. 
7. The teleological function of a historical kind member is defined by the contribution made by ancestral kind members to the stability and effect of a more general historical system.

Because replication and selection are general processes, historical kinds obtain outside of biology. As I describe in the next section, cultural forms of replication, reproduction, and selection carve out induction-supporting historical kinds with normative properties (teleological functions) in a way that is analogous to genetic replication, reproduction, and natural selection.

\section{GENDER KINDS ARE HISTORICAL KINDS}

If genders are historical kinds, then being a woman or a man is not a matter of possessing some set of biological or psychological properties, as these are merely probabilistic indicators of a deeper historical unity. Nor, for the same reason, is it to occupy a certain social position (Haslanger). Being a woman or a man, I now argue, is to have the right sort of origin and replicative history in relation to a more fundamental historical kind-a replicating gender system.

\section{A. The Historical Gender System}

By way of analogy, consider first what it is to be a member of the historical kind "1990 Nissan Sentra" (hereafter "Sentra"). Sentras are replicated systems. The reason that two token Sentras tend to have good gas mileage, front-wheel drive, and a faulty driver's door hinge is because they have been reproduced from the same historical design plan. Sentras consist of various subparts, such as the fuel exhaust, transmission, and radiator, all of which have separate but interdependent lineages. The reason that Sentras were reproduced was, first, because these subcomponents achieved a stable interdependency, and second, the overall effect of this system satisfied the interests of consumers and carmakers more so than competitor systems.

Now consider one of these subparts, the kind "Sentra transmission." Sentra transmissions are historical kinds because individual tokens are reproductions of a lineage (or "line," to adopt the industry lingo) of Sentra transmissions. On account of their history of reproduction under past selection pressures, Sentra transmissions also possess a teleological function. To identify this function we ask, "how did ancestral transmissions contribute to the stability and selected-for effect of the Sentra system?" The answer is the system-relative role (or Cummins function) shifting gears in Sentras. An individual hunk of steel is a Sentra transmission if it has been designed to shift gears in Sentras. Hunks of steel are so designed if they have been copied directly from other Sentra transmissions or built from a historical blue- 
print for Nissan transmissions. On the other hand, a molecular duplicate of a Sentra transmission created in a junkyard lightning storm is not a member of the kind Sentra transmission because it does not have the right history. There is also no sense in which it could malfunction. ${ }^{35}$

My claim is that a gender system should be analyzed in much the same way as the historical kind "1990 Nissan Sentra" and that the components of a gender system should be analyzed in much the same way as the historical components of a Sentra. It is possible to discern several processes that, through their causal interdependence, have led to the selection, maintenance, and ongoing reproduction of gender systems. The system is homeostatic, which is to say that its various components have achieved a stability that is resistant, though not impervious, to change. It does not follow that the system is necessary, and it certainly does not follow that the system is desirable or ethical (see Secs. V.C and VI.B.3). I propose that the components of a binary ${ }^{36}$ gender system include:

1. Binary sexual categories: The sexual categories male and female as defined by chromosomes, reproductive organs, and secondary sexual characteristics. On the other hand, intersexual categories, while biologically real, are not a part of extant gender systems.

2. Conceptual gender dualism: The tendency for individuals to think and categorize in terms of the masculine and feminine binary, including but not limited to (a) gender stereotypes: the association between females and feminine traits and males and masculine traits; $(b)$ correspondence bias: the interpretation of others' behavior as being caused by inner dispositions rather than situational constraints, ${ }^{37}$ for example, the assumption that gendered behavior is the product of psychology and physiology rather than social expectancies; and $(c)$ injunctive gender norms: the normative idealization between sex and gender, the moral disapproval of individuals' deviation from gender norms, and the moral

35. Fred Dretske, "Absent Qualia," Mind and Lanquage 11 (1996): 78-85; Millikan, Language, Thought, and Other Biological Categories.

36. There is no a priori reason to insist that all gender systems must be binary or that a token binary system must remain binary (see Sec. VI.B.3 for a discussion of the mutability of gender systems). However, it is likely that the dimension of a gender system is consistent across components (i.e., it is a ternary system throughout, or a quaternary system throughout, and so on). My focus in this article will be on binary gender systems.

37. See Alice Eagly, Wendy Wood, and Amanda Diekman, "Social Role Theory of Sex Differences and Similarities: A Current Appraisal," in Developmental Social Psychology of Gender, ed. Thomas Eckes and Hanns M. Trautner (Mahwah, NJ: Erlbaum, 2000), 123-74, 137. 
approval of individuals' conformity to gender norms.

3. Gender identity (or gender self-concept): The process whereby one identifies with a particular gender role, conceptualizes oneself as gendered, and interprets injunctive gender norms as applicable to oneself.

4. Binary gender socialization practices: Including but not limited to sex segregation, caregiver dispositions toward male and female children, and patterns of sexual objectification. ${ }^{38}$

5. Social and legal institutions: Including but not limited to gender differences in the law, civil rights, and pornography.

6. Binary gendered artifacts: Including but not limited to masculine and feminine toys, clothing styles, rituals, and role models.

7. Binary gender roles for individuals: The roles 'man' and 'woman', including position in a social hierarchy, division of labor, agentic versus communal personal characteristics, and differences in bodily presentation. ${ }^{39}$

Components 1-7 are causally interdependent: their individual histories of reproduction are enforced and facilitated by one another, much like the elements of an ecosystem or the components of a car.

Here is a simplified demonstration. Individuals are more likely to correlate aggressive behavior, agentic psychology, and entrepreneurship with perceived or imagined males and passive behavior, communal psychology, and domestic skill with perceived or

38. On sexual objectification, see Barbara Fredrikson and Tomi-Ann Roberts, "Objectification Theory: Toward Understanding Women's Lived Experiences and Mental Health Risks,” Psychology of Women Ouarterly 21 (1997): 173-206.

39. In philosophy and the social sciences, the expression 'social role' is ambiguous between at least three meanings: (1) the characteristic traits and behavior of social role occupants, (2) the cultural representations and expectations for characteristic traits and behaviors of social role occupants, and (3) the social identity of social role occupants. Researchers in sociology tend to use the expression to refer to meaning 1, and researchers in psychology tend to use the expression to refer to meaning 2 (Eagly, Wood, and Diekman, "Social Role Theory," 130-31 n. 1). As will become clear below, my use of the expression 'gender role' refers to the first of these meanings: characteristic traits and behavior. The conceptual gender dualism component of the gender system refers to meaning 2 , and the gender identity component refers to meaning 3. In contrast, Mallon's HPC account of social kinds uses the expression "social role kind" to refer to meaning 2. According to Mallon, social role kinds qua conceptual/labeling practices act as homeostatic mechanisms which causally structure the characteristic properties and behaviors of social role occupants. While there is much that Mallon and I agree on, the views are quite different in this respect. The naturalized social kinds that emerge on Mallon's view are cultural/conceptual entities, e.g., masculine social role. On my view, the naturalized social kinds are actual historical lineages of men and women, these lineages selected for by cultural reproductive processes. More generally, the views are different in their use of history. See the discussion in Sec. VI.A. 
imagined females. ${ }^{40}$ Differential socialization, often implemented through gender-coded artifacts and role models, exerts normative pressure on sexed individuals to conform behaviorally to these gender stereotypes. This normative pressure consists in social rewards for sex-appropriate behavior and social disapproval for sex-inappropriate behavior. As a result, individuals often conform to gender expectations. ${ }^{41}$ Gender expectations also cause individuals to internalize norms and thereby self-identify with their assigned gender. Children who are socialized within a gender system contribute to this normalization at a very early age, often by enforcing gender expectancies within sex-segregated peer groups. ${ }^{42}$ In general, when individuals act in ways that are appropriate to their gender role, perceivers use a "correspondence bias" to infer inner (e.g., sexual, psychological) causes of behavior rather than contextual or social causes. ${ }^{43}$ Various legal and social institutions, such as pornography, function to justify the correspondence bias by portraying the sexes as naturally occupying positions in the gender hierarchy. ${ }^{44}$ And so on.

\section{B. Teleological Gender Function}

Reproduced members of a historical gender kind possess a teleological gender function if the gender lineage of which they are a reproduction resulted from selective processes. One method for ascribing teleological gender properties is to appeal to the evolutionary and reproductive pressures faced by ancestral males and females. Several evolutionary psychologists contend that aspects of current gender roles are phenotypic expressions of sex-specific genotypes selected for under ancestral evolutionary pressures. Social learning theorists disagree, arguing that cultural rather than genetic factors explain gen-

40. Alice Eagly and Antonio Mladinic, "Gender Stereotypes and Attitudes toward Women and Men," Personality and Social Psychology Bulletin 15 (1989): 543-58; Robert Baron, Gideon Markman, and Azita Hirsa, "Perceptions of Women and Men as Entrepreneurs: Evidence for Differential Effects of Attributional Augmenting," Journal of Applied Psychology 86 (2001): 92329.

41. M. L. Snyder, "On the Self-Perpetuating Nature of Social Stereotypes," in Cognitive Processes in Stereotyping and Intergroup Behavior, ed. D. L. Hamilton (Hillsdale, NJ: Erlbaum, 1981), 183-212; James M. Olson, Neal J. Roese, and Mark P. Zanna, "Expectancies," in Social Psychology: Handbook of Basic Principles, ed. E. T. Higgins and A. W. Kruglanski (New York: Guilford, 1996), 211-38.

42. Eleanor E. Maccoby, "Gender as a Social Category," Developmental Psychology 24 (1988): 755-65; Beverly Fagot, Carie Rodgers, and Mary Leinbach, "Theories of Gender Socialization," in The Developmental Social Psychology of Gender, ed. Thomas Eckes and Hanns Trautner (Mahwah, NJ: Erlbaum, 2004), 65-89.

43. Eagly, Wood, and Diekman, "Social Role Theory."

44. For example, Catharine MacKinnon, Feminism Unmodified (Cambridge, MA: Harvard University Press, 1987). 
der differences and the structure of extant gender systems. I will not review this debate here but will note that the historical analysis to be offered is logically consistent with both positions. If there are important genetic determinants of current gender differences, then biological properties constrain the possible structures of historical gender systems. ${ }^{45}$ However, I claim it a virtue of the historical account that it is compatible with, and provides an ontological framework for, the social learning explanation. (An analogous virtue is claimed by philosophers of mind who defend the thesis that mental states are multiply realizable functional states. While the thesis of multiple realizability does not rule out the possibility that immaterial souls realize mental states, the central motivation for this view is the empirical possibility that a wide variety of physical states realize mental states.) In order to develop this framework, then, I will assume that the structure of extant gender systems and the content of current gender roles are culturally rather than biological determined. Relatedly, I will assume that it is possible for social communities to realize alternative homeostatic gender systems-systems that rational agents would agree are more suitable for the fundamental interests of all autonomous individuals.

How, then, might cultural processes reproduce historical gender kinds such that they possess teleological functions? Put slightly differently, what cultural mechanisms favor, and account for the biased transmission of, gender variants? With respect to current gender systems, the institutions already in place (media, schools, medical profession, etc.) play a central role in favoring the transmission of particular gender variants. I sketch this institutional role for the selection of the binary structure of sexual categories below, and in Section V.C, I describe how institutions favor particular content variants for the gender roles men and women. Still, we require an account of how the institutions that originally structure a gender system could result from cultural mechanisms of selective retention rather than from accident or biological determination.

There is now evidence and reasonable speculation about the or-

45. Analogously, it is the physical difference between a collection of steel and a collection of cotton that explains why the former but not the latter can play the historical role of shifting gears in Nissan Sentras. See Simon Baron-Cohen, The Essential Difference. Male and Female Brains and the Truth about Autism (New York: Basic Books, 2004), for an example of a view on which biological differences between the sexes would constrain certain aspects of gender role (e.g., personal and interpersonal characteristics). See Rebecca Jordan-Young, Brain-Storm: The Flaws in the Science of Sex Differences (Cambridge, MA: Harvard University Press, 2010); and Cordelia Fine, Delusions of Gender: How Our Minds, Society, and Neurosexism Create Difference (New York: Norton, 2010), for recent challenges to empirical claims that link sex-specific biological differences to gender differences. 
igins of patriarchy. According to many social scientists and historians, physical differences between the sexes (e.g., upper body strength, reproductive capacity), in conjunction with technological, social, and ecological contextual factors (e.g., the transition from shifting cultivation to plough cultivation), caused a division of labor with males more likely farming and females more likely performing family work. ${ }^{46}$ However, it is the institutions that were created during the cultural interpretation and assimilation of this division of labor that arguably best explain the creation of gender hierarchy. It is likely that groups developed belief systems that described women as essentially (rather than contextually) reproducers and caregivers and men as essentially public and resource providers. ${ }^{47}$ Through socialization, families culturally reproduced these beliefs because they better secured resources for production-dependent females. ${ }^{48}$ Eventually, these belief systems were codified in law. ${ }^{49}$ It is also likely that increasingly complex socioeconomic conditions, such as those brought on by sedentary agriculture, led to the sexual control of women. ${ }^{50}$ In part because females represented a biological source of new laborers, groups developed cultural institutions such as incest taboo, patrilineal inheritance, and the forceful exchange of women that regulated human reproduction and kinship relations. These institutions played a central role in establishing women's social role as reproducer and men's social role as controller of resources. ${ }^{51}$

46. Ester Boserup, Woman's Role in Economic Development (London: Allen \& Unwin, 1970); Gerda Lerner, The Creation of Patriarchy (New York: Oxford University Press, 1986); Marvin Harris, "The Evolution of Human Gender Hierarchies: A Trial Formulation," in Sex and Gender Hierarchies, ed. Barbara D. Miller (New York: Cambridge University Press, 1993), 57-80; Wendy Wood and Alice Eagly, "A Cross-Cultural Analysis of the Behavior of Women and Men: Implications for the Origins of Sex Differences," Psychological Bulletin 128 (2002): 699-727.

47. Wood and Eagly, "Origins of Sex Differences"; Alberto Alesina, Paola Giuliano, and Nathan Nunn, "On the Origins of Gender Roles: Women and the Plough." NBER Working Paper no. 17098 (National Bureau of Economic Research, Cambridge, MA, 2011).

48. See Torben Iversen and Frances Rosenbluth, Women, Work, and Politics: The Political Economy of Gender Equality (New Haven, CT: Yale University Press, 2010). The authors argue that men's greater bargaining power-a power that resulted from their mobile farming skills - "translates into norms as parents socialize their children to make the best use of opportunities available to them.... Where economic efficiency gives males a bargaining advantage on account of greater mobility of their human capital from a gendered division of labor, families do best by socializing a daughter to cultivate the femininity that will help her win a good man and the docility that will help her keep him" (33).

49. See Lerner, Patriarchy.

50. See Claude Lévi-Strauss, The Elementary Structures of Kinship (Boston: Beacon, 1969); Gayle Rubin, "The Traffic in Women: Notes on the Political Economy of Sex," in Toward an Anthropology of Women, ed. Rayna Reiter (New York: Monthly Review, 1975), 157-210; Lerner, Patriarchy; Wood and Eagly, "Origins of Sex Differences."

51. Lerner, Patriarchy. 
Once in place, these and other cultural institutions reproduce the interdependences of a gender system regardless of the presence of the initial contextual factors. For instance, societies that leave an agricultural economy persist in the maintenance of the gender roles and norms that originated in agricultural socioeconomic conditions. Remarkably, Alesina, Giuliano, and Nunn found that present-day female descendents of historical societies that employed plough technology have lower rates of entrepreneurship, participation in politics, and participation in the labor force..$^{52}$ These authors also found that descendents of historical plough societies are more likely to have attitudes that favor gender hierarchy. These considerations identify historical soil conditions (conditions that differentially benefited plough use) and cultural modes of reproduction, rather than evolutionary conditions and biological modes of reproduction, as explanatory of the emergence and maintenance of historical gender systems.

We can determine the teleological function of a gender kind by its past favorable effect toward the stabilization of the gender system, this favorable effect accounting for the reproduction of members of that kind. For example, the binary structure of sexual categories was culturally favored over other structures (ternary, quaternary, etc.) because it better comported with other gender dualisms, thereby stabilizing the gender system. On the other hand, a structure of five sexual categories that is inclusive of (biologically real) intersexual categories does not contribute to, and in fact destabilizes, the structure of interdependencies within a gender system. For this reason, intersexual categories have been culturally selected against. Various institutions, including the family and medical professions, carry out this selective process by marginalizing intersexuals and in many cases surgically reassigning intersexuals as either male or female. This makes clear one sense in which sex is "socially constructed." The sexual categories male and female are to play specific roles within a historical, replicating system. Calling a baby "female" is prescriptive because it indicates, in reference to historically defined norms, how this individual is supposed to interact with other components of a socially replicated system. There is no such historical role for intersexuals.

\section{The Historical Roles of Men and Women}

The current proposal does not aim to establish the essential properties or the teleological gender functions for men and women through conceptual analysis. It is rather through empirical investigation of a gender system and its replicative history that we can discover the on-

52. Alesina, Giuliano, and Nunn, "Women and the Plough." 
tological status of its subparts. ${ }^{53}$ The difference between empirical and conceptual analyses of gender kinds is perhaps most clear when we examine cases in which the surface properties of an item cross classify the kind status of an item. For a type of toy or a type of clothing to be gendered is not for it to have a certain "masculine" or "feminine" appearance-for it to look and operate like a truck versus a doll or a necktie versus a skirt. A type of toy is a boy's toy and a type of clothing is women's clothing on the basis of the type's historical role in the gender system. Many of the superficial features of an item that are typically associated with gender status ("rough," "pink") do not define the category, then, but are property syndromes that occur probabilistically on the basis of the kind's historical source of property correlation.

For example, items that exemplify the nonhistorical properties that conventionally define skirts-draped, cone-shaped, and leg-covering-are members of a masculine kind if they belong to a historical lineage of a masculine artifact kind. That is, if a draped, cone-shaped, and leg-covering garment is a reproduction of a lineage of garments whose historical role in a gender system is the symbolization of masculine gender, then the item is a member of a historical, masculine artifact kind. Thus Scottish kilts form a masculine artifact kind on account of the historical contribution that ancestral kilts made to a gender system. An individual piece of clothing is a kilt if it has been copied from or designed from other kilts. Now, suppose such a kilt were never worn and instead spent its career hanging from a window and blocking sun. The item is still a member of the historical and masculine kind kilt, although it never performs its teleological function of symbolizing masculinity. On the other hand, if a Scotsman is in a pinch and borrows a garment that was designed as a women's skirt, though the item has the current Cummins function of symbol-

53. The description of the interacting components of the gender system is drawn from empirical work in the fields of developmental psychology, sociology, and social psychology, as well as the interdisciplinary theoretical framework of role theory. For a review of role theory in the sociological tradition, see B. J. Biddle, "Recent Developments in Role Theory," Annual Review of Sociology 12 (1986): 67-92. For a review of role theory in the developmental psychology and social psychology traditions, see Eagly, Wood, and Diekman, "Social Role Theory." This empirical commitment also reserves an essential role for feminist scholarship in the epistemology of gender categories. Feminist contributions include the development of new theory, critical investigations that reveal gender-related presuppositions in both folk and empirical theory, and critical evaluation of the import of empirical observations (see Lynn Hankinson Nelson, "Epistemological Communities," in Feminist Epistemologies, ed. Linda Alcoff and Elizabeth Potter [New York: Routledge, 1993], 121-59; Helen Longino, "Subjects, Power, and Knowledge: Description and Prescription in Feminist Philosophy of Science," in Alcoff and Potter, Feminist Epistemologies [1993], 101-20). 
izing masculinity and covering a male's legs, it is not a member of the historical kind kilt. ${ }^{54}$

In order to determine the teleological function of the gender roles men and women, we must investigate the contributions made by the historical lineages of men and women toward the stabilization of a gender system. Plausible candidates for these contributions include, but are not limited to, the following features:

1. Social hierarchy: Women have less status and power than men. ${ }^{55}$ "Status" and "power" refer to social resources, possession of which enable individuals and groups to better assert their will relative to individuals and groups that do not have status and power. Examples of power include determining public policy, controlling financial institutions, and having better access to high-status and high-paying positions.

2. Division of labor: Women are more likely to perform household labor, and men are more likely to perform paid labor. Although this division is not as sharp as it once was, recent reviews indicate that women perform twice as much household labor as men. ${ }^{56}$ There is also gender segregation within the paid labor market, with more women than men having

54. Kilts possess a type of teleological function that Millikan terms a 'coordinating function' (see, esp., Ruth Millikan, Language: A Biological Model [New York: Oxford University Press, 2005]). In Scotland, draped cone-shaped garments coordinate reference to men, and elsewhere such garments coordinate reference to women. As is true of arbitrary signifiers in natural language, history of use rather than form determines an item's coordination function: it is because the item solved a coordination problem, and not because it has any particular intrinsic features, that it was reproduced and formed a historical lineage with the function of solving that particular coordination problem. How forms get initially slotted to play a coordinating role is often arbitrary, but once reproduced on the basis of its ability to solve the coordination problem, the form acquires the relevant coordinating function. Certain gendered artifacts and clothing styles have forms that are arbitrarily related to their coordinating function. However, most historical gender kinds were selected for because of some feature or features that are specific to these items and which explain their ability to contribute to the stabilization of the gender system. For example, it is not the case that pornography is arbitrarily related to the objectification of women, or that rough play is arbitrarily related to the socialization of males, or that injunctive gender norms are arbitrarily related to gender identity and elective cosmetic surgery, and so on. I am grateful to an anonymous reviewer from this journal for helping me recognize the importance of this point.

55. US Bureau of Labor Statistics, "Highlights of Women's Earnings in 2008," Report 1017 (July 2009), US Department of Labor, US Bureau of Labor Statistics, Washington, DC, 1-91; Eschel M. Rhoodie, Discrimination against Women: A Global Survey of the Economic, Educational, Social and Political Status of Women (Jefferson, NC: McFarland, 1989).

56. Scott Coltrane, "Research on Household Labor: Modeling and Measuring the Social Embeddedness of Routine Family Work," Iournal of Marriage and Family 62 (2000): 1208-33. 
jobs that require skills associated with household labor, ${ }^{57}$ and gender segregation within household labor, with women more likely to perform "core housework" (cooking meals, housecleaning, laundry) and men more likely to perform repairs, outdoor chores, and financial tasks. ${ }^{58}$

3. Personal and interpersonal characteristics: Men on average have more agentic (or instrumental) traits, and women on average have more communal (or expressive traits). In particular, men are more likely to seek independence and mastery, while women are more likely to seek solidarity and interpersonal connection. Men are more likely to be assertive and aggressive, while women are more likely to be tender-minded. ${ }^{59}$

4. Body management: Women and men pursue different modes of bodily self-presentation. This includes, but is not limited to, different "technologies of body management" (as Bordo terms it), such as makeup, elective cosmetic surgery, and steroids, a focus on youthful versus sophisticated appearance, an emphasis on weight management versus muscle management, and the higher rate at which women smile relative to men. ${ }^{60}$

We can assume that ancestral males and ancestral females exhibited a range of social and behavioral traits. Among these competing gender role cultural variants, sexed individuals who exemplified properties 1-4 in conformity to the dualisms that structure a gender system acted to stabilize that system more than individuals who did not exemplify these properties. If these gender roles were culturally reproduced on account of this stabilizing effect, we can conclude that they were culturally selected for. On the etiological account of functions sketched earlier, the binary sets of properties described in properties 1-4 constitute the teleological functions of men and women.

57. Mariko L. Chang, "The Evolution of Sex Segregation Regimes," American Journal of Sociology 105 (2000): 1658-1701.

58. Suzanne M. Bianchi, Melissa A. Milkie, Liana C. Sayer, and John P. Robinson, "Is Anyone Doing the Housework? Trends in the Gender Division of Household Labor," Social Forces 79 (2000): 191-228.

59. For empirical reviews, see Alice Eagly and Wendy Wood, "Explaining Sex Differences in Social Behavior: A Meta-analytic Perspective," Personality and Social Psychology Bulletin 17 (1991): 306-15; and Alan Feingold, "Gender Differences in Personality: A Meta-analysis," Psychological Bulletin 116 (1994): 429-56.

60. Judith A. Hall, "How Big Are the Nonverbal Sex Differences? The Case of Smiling and Sensitivity to Nonverbal Cues," in Sex Differences and Similarities in Communication: Critical Essays and Empirical Investigations of Sex and Gender in Interaction, ed. D. J. Canary and K. Dindia (Mahwah, NJ: Erlbaum, 1998), 59-81. 
Various cultural mechanisms favored these gender roles and explain their frequency in a population. MacKinnon, Lerner, Acker, and others have made clear that many institutions are inherently structured so as to exclude women in the allocation of status and power; gendered individuals-specifically women-often exemplify gender role properties under coercive conditions. ${ }^{61}$ Coercion can also be more subtle. Women are looked at more often than men. ${ }^{62}$ The objectifying effect of the male gaze often leads to self-objectification, which in turn causes women to adopt a stricter regimen of bodily presentation. ${ }^{63}$ More generally, institutions socially reward sexed individuals who conform to gender role properties and punish individuals who fail to conform. With respect to body management, Fredrickson and Roberts report that obesity more negatively affects women's social mobility than men's, that "women deemed unattractive by their coworkers are described more negatively than comparably unattractive men," and that women experience job discrimination on the basis of "unfeminine appearance." ${ }^{64}$ In general, there is no shortage of empirical evidence describing how sexed individuals are marginalized and privileged on the basis of whether they exemplify gender role properties.

The process through which institutions favor gender role variants can also be expressed within Richerson and Boyd's theoretical framework for cultural selection. ${ }^{65}$ According to Richerson and Boyd, prestige bias and conformist bias are important forces explaining the preferential adoption of cultural variants. Prestige bias refers to the tendency of individuals to imitate and copy those in prestigious positions. Conformist bias refers to the tendency for individuals to copy behaviors that are common. Richerson and Boyd claim that a cultural variant is selected for if the effects of holding that variant cause the holder to be imitated, in which case the variant is more likely to be transmitted to others. Given prestige and conformist bias, this means that a cultural variant is more likely to be selected if it causes its bearer to become more common and/or more prestigious. It follows that the cultural forces determining what counts as prestigious and

61. Catharine MacKinnon, "Feminism, Marxism, Method and the State: An Agenda for Theory," Signs 7 (1982): 515-44; Lerner, Patriarchy; Joan Acker, "Hierarchies, Jobs, Bodies: A Theory of Gendered Organizations," Gender and Society 4 (1990): 139-58.

62. Judith A. Hall, Nonverbal Sex Differences: Communication Accuracy and Expressive Style (Baltimore: Johns Hopkins University Press, 1994).

63. Fredrikson and Roberts, "Objectification Theory."

64. Ibid., 178.

65. See Peter J. Richerson and Robert Boyd, Not by Genes Alone: How Culture Transformed Human Evolution (Chicago: University of Chicago Press, 2005). 
what types are common function as important mechanisms of cultural selection.

Applying this framework, several components of the gender system-particularly gender socialization and gender institutionsfunction as important mechanisms for the cultural selection of gender role variants. It is well known that the media grants prestigious status to men and women who exemplify traditional gender role properties. ${ }^{66}$ Given prestige bias, we can then expect that individuals who adopt these gender roles are more likely to be copied and imitated. In a society where individuals are segregated on the basis of sex and injunctive gender norms apply, we can expect that within segregated groups sex-appropriate gender role variants will be more common than sex-inappropriate variants. Given conformist bias, we can then expect that individuals who adopt these standard gender roles will be copied and imitated. Note also that the exclusion of women from positions of power and status precludes these women from serving as models of power and status. Moreover, because parents serve as models to children, institutions that mark nonconformist men and women as less respectable and less worthy of marriage and/or parenting (Assyrian veiling, female genital mutilation, and hate speech directed at powerful women, to name a few) also count as mechanisms for the selection of gender-role variants.

Two caveats about teleological gender function deserve emphasis here. First, ancestral men and women need not have exemplified all, most, or even any of the behavioral, psychological, and positional properties that constitute their gender role. It is only necessary that enough sexed individuals exemplified at least some of these properties enough of the time. The exact thresholds of these variables that is required for the selection of a role depends on the selective pressures that exist for the wider historical system and also the role's contribution to that system. For example, in the case of human sperm, for which the selected historical role is the fertilization of female ova, it was only necessary that a very tiny fraction of sperm performed this role.

Second, the type of normativity that attaches to an item in virtue of its teleological function is not equivalent to, and often in opposition to, evaluative and prescriptive norms ${ }^{67}$ The teleological function of a virus is to spread and infect, and the teleological function of a

66. See, e.g., Sandra-Lee Bartky, Femininity and Domination: Studies in the Phenomenology of Oppression (New York: Routledge, 1990); and Susan Bordo, Unbearable Weight: Feminism, Western Culture, and the Body (Berkeley: University of California Press, 1993).

67. Ruth Millikan, "Biofunctions: Two Paradigms," in Ariew, Cummins, and Perlman, Functions (2002), 113-42, 116. 
cruise missile is to deliver a warhead. But we would not say that a virulent virus satisfies the evaluative and prescriptive norms of human health, and it is debatable whether cruise missiles satisfy evaluative and prescriptive norms. Similarly, the statement that women, on account of their teleological function, are "supposed to" perform a historical gender role is neither evaluative nor prescriptive. The semantic sense of normativity that follows from the historical analysis of gender is elliptical for a description of the causal relationship between an individual, with a certain ontogenetic history, and a system of social interdependencies, with a certain phylogenetic history. This is an empirical norm, discoverable through investigating historical relations, although it is likely explanatory of many of the felt pressures of everyday gendered life.

These different senses of normativity have important implications for the political negotiation of gender. Consider someone who judges that women ought (in the evaluative/prescriptive sense) to have less power, resources, and opportunities than men. Such a person positively values and prescribes current teleological gender norms. However, if the argument given for this position is "men and women ought (in the prescriptive/evaluative sense) to perform traditional gender roles because men and women ought (in the historical/teleological sense) to perform traditional gender roles," then this argument either begs the question or is invalid because it equivocates on the term 'ought'. Arguing for evaluative gender norms requires careful consideration of ethical parameters such as rational autonomy, human flourishing, social justice, and equal rights. These considerations inform much feminist theory in which evaluative and prescriptive norms often describe social relationships that require gendered individuals to act in ways that would result in their failing to satisfy the teleological norms of their gender roles. To illustrate, many feminists evaluate elective cosmetic surgery ${ }^{68}$ and obsessive dieting ${ }^{69}$ as harmful to women, while noting that these practices are replicated and normative within the current gender system.

While evaluative gender norms are not deducible from historical gender norms, the historical and teleological status of gender is still important for evaluative and political discussions about gender. For one, it is politically useful to have adequate descriptive theories of the targeted social groups. While evaluative deliberations determine our political goals, we cannot chart a political course to these goals (and thus we cannot determine what obstacles lie between us and these

68. See, e.g., Kathryn P. Morgan, "Woman and the Knife: Cosmetic Surgery and the Colonization of Women's Bodies," Hvpatia 6 (1991): 25-53.

69. See, e.g., Bordo, Unbearable Weight. 
goals) without an adequate account of our current social and political location. The proposed ontology interprets the destination point of gender egalitarianism as a future gender system that culturally reproduces men and women so that they are supposed to have (in the historical/etiological sense) equal status, power, and labor opportunities. The proposed ontology helps locate the departure point by describing the natures and boundaries of the targeted social groups. ${ }^{70}$

Furthermore, the proposed historical ontology construes the social and political equality of men and women as a theoretical possibility. On the other hand, gender ontologies that are essentially hierarchical (such as Haslanger's) theorize egalitarianism as incompatible with the preservation of the genders men and women (see Sec. VI.B.3). This theoretical point has practical implications. I agree with Haslanger that our gender categories ought to help us meet our political goals, but if our political goal is gender equality, it may be more politically useful to have gender categories for which the attainment of this goal requires us to change, rather than eliminate, the groups men and women. That is, it may be difficult to motivate gender elimination to the degree to which people identify with their gender. In Section VI, I further explore the implications of the proposed historical ontology for the political status of men and women.

\section{The Ontogenetic Processes through Which Individuals Become Members of a Historical Gender Kind}

One is not born a man or a woman any more than a hunk of steel is born a Sentra Transmission. A hunk of steel comes to belong to the historical kind Sentra Transmission if it is a reproduction of a lineage of Sentra Transmissions-if it is sculpted and pounded according to a historically specified Nissan design plan. Similarly, a collection of organic material comes to be a member of the historical kind human heart if it is constructed according to a genetic design that has the function of producing hearts. In this section, I describe the ontogenetic processes through which sexed individuals are made reproductions of the lineages of men and women and thereby become members of the historical kinds men and women.

There are many levels at which reproduction occurs in a gender system and many mechanisms that carry out reproductions. Our concern here is the mechanisms that assign individuals to historically defined gender roles, thereby producing reproductions of men and women. The most important and familiar process is differential socialization. New parents describe their infants according to sex ste-

70. In this respect, what Haslanger terms the ameliorative/analytic project (see $\mathrm{n}$. 17) cannot be considered in abstraction from the descriptive project. 
reotypes even when infants do not vary in length, weight, or Apgar scores. ${ }^{71}$ Parents talk differently to their child on the basis of sex, with boys receiving more directives, prohibitions, and disparaging names (e.g., "wiseguy," "nutcake") and girls receiving more questions, supportive speech, and twice as much emotion talk. ${ }^{72}$ Sex segregation, which occurs uniformly in both school and peer groups, significantly amplifies the effects of differential socialization. ${ }^{73}$ Particularly effective are the replicative mechanisms that occur through what Bem and Bem call the "power of an unconscious ideology": ${ }^{74}$ well-meaning people who consciously subvert gender norms unconsciously enact those norms in their daily interactions with children and peers; they are unwitting vehicles for the successful functioning of other components of the gender system (such as conceptual gender dualism and differential socialization) that have the historical purpose of producing gendered individuals.

In sum, both conscious and unconscious design mechanisms mold infants as reproductions of historical men and women from the moment they are born. Through these processes an individual comes to participate in a lineage of men or women and thereby becomes a member of the historical kind men or women. While biological sex marks an individual as target for particular ontogenetic processes, membership in a gender lineage does not require membership in any particular sexual category. It is possible, and perhaps actual, that males have been made reproductions of women and females have been made reproductions of men, provided they underwent the relevant ontogenetic processes. For example, David Reimer-a biological male socialized as a woman-might be construed as a woman on this analysis. ${ }^{75}$

71. Jeffrey Z. Rubin, Frank J. Provenzano, and Zella Luria, "The Eye of the Beholder: Parents' Views on Sex of Newborns," American Journal of Orthopsychiatry 44 (1974): 512-19.

72. Linda L. Carli and Danuta Bukatko, "Gender, Communication, and Social Influence: A Developmental Perspective," in Eckes and Trautner, The Developmental Social Psychology of Gender (2004), 295-323.

73. Fagot et al., "Theories of Gender Socialization."

74. Sandra Bem and Daryl Bem, "Homogenizing the American Woman: The Power of an Unconscious Ideology," in Feminist Frameworks: Alternative Theoretical Accounts of the Relation between Men and Women, ed. Alison Jaggar and Paula Rothenberg Struhl (New York: McGraw Hill, 1978), 10-22. See also Iris Marion Young, Justice and the Politics of Difference (Princeton, NJ: Princeton University Press, 1990).

75. For a description of Reimer's case, see John Colapinto, "The True Story of John/Joan," Rolling Stone, December 11, 1997, 54-97. In order to analyze a case like this it is important to $(a)$ separate gender from gender identity, and $(b)$ recognize that gender boundaries might be vague. Concerning this second point, it is relevant that while gender socialization begins at birth, Reimer's sexual reassignment surgery 
But here is where the importance of the historical approach comes into focus. For an individual to be a woman is not for her to exemplify the four properties that constitute women's historical gender role-to be subordinated, tender-minded, present her body according to the norms of the fashion-beauty complex, and perform more housework. To be a woman, rather, is to be a reproduction of a historical lineage, in which case one is only supposed to exemplify the features of the historical gender role. If a particular female has undergone the ontogenetic process through which one exemplifies a participatory relation to a lineage of women, then even if she fails to exemplify any of the properties of women's historical gender role, she is still a woman because she has the right history. The converse of this point is that an individual who exemplifies all of the properties of women's historical role but who does not descend from women is not, in fact, a woman. This is true of "swamp-woman," a gender variant on the familiar thought experiment. If a lightning storm were to strike a swamp and create a being that perfectly exemplified the properties that define women's historical gender role, swamp-woman would not be a member of the historical kind woman because swamp-woman does not have the correct history.

\section{E. Historical Gender Kinds and Teleofunctional Gender Kinds}

It is important to distinguish between token replicating gender systems and types of replicating gender systems. Token replicating gender systems are individuated historically, much like the biological taxa that are studied in the cladistic school of phylogenetic systematics. Cladists maintain that Homo sapiens from the present and the late Pleistocene period are members of the same species because they participate in the same unfractured lineage. Cladists also group traits as homologues on the basis of common descent. For example, "human limbs are homologous with avian limbs because both are derived from the same distant, ancestral tetrapod body plan." ${ }^{76}$ The historical approach to gender applies the same taxonomic method. The US gender system of the 1950s and the US gender system as it exists today are members of the same historical kind because the current system is a descendent of the historical system. Contemporary American women and American women from the 1950s are members of the same historical kind because they descend from the same ancestral population of American women. It is a virtue of cladistic classification in biology that it reconciles species unity with the fact of evolutionary

did not take place until Reimer was 22 months old. I discuss vague boundaries and transgendered individuals in Sec. VI.B.3). I thank an anonymous referee for pointing out the relevance of Reimer's case to the proposed analysis.

76. Griffiths, Emotions, 213-14. 
change, and it is a virtue of the historical kind approach to gender that it can provide a principled account of the unity of women and the unity of men that is consistent with the fact of social change.

On the other hand, there is no significant historical unity between the American gender system and the Japanese gender system. American women and Japanese women do not descend from the same ancestral population of women and are therefore not members of the same historical gender kind. Yet, the Japanese gender system and the American gender system exemplify roughly the same structure of interdependencies. That is, the systems are the same type of replicating gender system, exhibiting patriarchal distribution of status and power, ${ }^{77}$ similar division of labor, ${ }^{78}$ and similar gender stereotypes. ${ }^{79}$ In the biological domain, phylogenetic systematists describe this type of phenomenon in terms of analogous (or homoplastic) traits. Analogous traits resemble one another as a result of parallel evolution rather than descent from a common ancestor. For instance, distinct evolutionary lineages have produced organisms with four-chamber hearts, and while human hearts are homologous to chimpanzee hearts, they are only analogous to eagle hearts. The reason that the functional organizations of human and eagle hearts resemble one another is that they share a common type of history. An important shared feature of eagle hearts and human hearts is their teleological function: they have in common the property of being supposed to pump separate streams of oxygen-rich and oxygen-depleted blood.

This point helps indicate the type of cross-cultural unity that exists for historically defined gender kinds. American and Japanese women are not members of numerically the same historical kind. However, the historical gender roles in each system are analogous. On account of their shared type of history, then, American and Japanese women are members of numerically the same teleofunctional gender kind. This means that both American and Japanese women can fail to satisfy their teleofunctional gender norm and yet both are still members in the cross-cultural teleofunctional gender kind (and, of course, they are still also members in their respective historical kinds). Similarly, a nonfunctioning human heart and a nonfunctioning eagle heart are both still members of the teleofunctional kind four-chambered heart.

77. Rhoodie, Discrimination against Women: A Global Survey.

78. Ibid.

79. John E. Williams, and Deborah L. Best, Measuring Sex Stereotypes: A Multinational Study (Newbury Park, CA: Sage, 1990). 


\section{ADJUDICATION BETWEEN HISTORICAL ESSENTIALISM, SOCIAL OBJECTIVISM, AND THE HPC ACCOUNT}

In this section, I compare historical essentialism to social objectivism and the HPC account with respect to the solutions they offer to the Commonality and Representation Problems. Because social objectivism is developed specifically as a theory of gender, it will receive extended comparison.

\section{A. Comparison between Historical Essentialism and the HPC Account}

Historical essentialism and the HPC account both model social kinds as explanatory, natural kinds, reference to which accommodates explanatory practices in the social sciences. By incorporating social kinds within the same broad ontological framework as species, electrons, and hurricanes, both accounts provide a similar and non-ad hoc solution to the Representation Problem. ${ }^{80}$

On the other hand, historical essentialism is better equipped than the HPC view to address the Commonality Problems. This follows from a difference in how the accounts understand the role of history in determining kind membership. The HPC view requires kind members to approximate an appropriate degree of (nonhistorical) feature similarity. Boyd is clear about this when he submits: "Even when the relevant homeostatic mechanisms crucially involve copying or information transfer-as is the case of biological species-I do not for better or worse, hold that HPC kinds are defined by reference to historical relations among members, rather than by reference to shared properties." ${ }^{81}$ Because HPC kinds are defined by both homeostatic mechanism(s) and shared properties, exemplification of historical properties (assuming these are the kind's homeostatic mechanism) is not sufficient for kind membership. The result, as Ereshefsky notes, is that "HPC's emphasis on similarity is at odds with phylogenetic approaches to taxonomy. HPC kinds are fundamentally similarity classes, whereas taxa are fundamentally genealogical entities." ${ }^{82}$ In contrast, historical essentialism does not grant a defining role to superficial, nonhistorical properties-reproduction from a historical

80. Family-resemblance property cluster accounts (e.g., Stoljar, "Concept of a Woman") do not share this empirical commitment (see Ron Mallon, "Human Categories beyond Non-essentialism," Iournal of Political Philosophy 15 [2007]: 146-68) for a comparison between HPC and family-resemblance property clusters). For this reason, they offer a less satisfactory response to the Representation Problem.

81. Richard Boyd, "Kinds, Complexity, and Multiple Realization: Comments on Millikan's 'Historical Kinds and the Special Sciences,"” Philosophical Studies 95 (1999): 67-98, 80.

82. Marc Ereshefsky, "Foundational Issues Concerning Taxa and Taxon Names," Svstematic Biology 56 (2007): 295-301, 296. 
lineage is sufficient for kind membershp. While reproductive properties tend to make kind members alike-and this is why historical kinds support induction and qualify as explanatory natural kinds-a historical kind's essence consists in historical properties rather than characteristic properties. Ereshefsky summarizes that, "for Boyd, similarity trumps historical connectedness." ${ }^{83}$ We can summarize Millikan's position, and more generally that of the historical essentialist, by claiming that historical connectedness trumps similarity. ${ }^{84}$

With respect to the Commonality Problem of universal gender properties, HPC's commitment to shared properties would require individual women and men to exemplify some subset of the gender role property cluster. No single gender feature is necessary, yet some unspecified percentage of the delimited gender role properties is necessary. In contrast, historical essentialism theorizes these features as probabilistic outcomes of gender reproduction but does not universally require any percentage of these features for membership in a gender lineage. Boyd's commitment to the importance of shared properties also restricts the extent to which a kind's defining properties can change. If there is not significant overlap between a kind's characteristic properties at times 1 and 2, then historical properties rather than characteristic properties secure kind unity-a possibility that Boyd explicitly denies. ${ }^{85}$ Applied to gender, this view sets a limit on the extent to which traditional gender roles can change while men and women retain kind identity. As I elaborate in Section VI.B.3, historical essentialism allows that men and women persist despite radical changes in gender role. Finally, the HPC view does not resolve the normativity problem. The defining property cluster establishes a normative ideal that can potentially marginalize those who do not exemplify enough of the cluster while privileging those who exemplify

83. Ibid., 296.

84. Mallon's HPC social role account (see Mallon, "Social Construction, Social Roles, and Stability") mentions Millikan's historical view but does not incorporate any of the explanatory resources of Millikan's view. Nor does Mallon distinguish Boyd's view from Millikan's historical commitments. In several places Mallon endorses HPC's dual emphasis on property cluster and homeostatic mechanism, which suggests a commitment to the importance of shared nonhistorical properties.

85. See Boyd, "Kinds, Complexity, and Multiple Realization," 82. Boyd allows this in the case of "natural individuals," adding that historical relations are "explanatorily central" for individuals but not kinds (see Boyd, "Homeostasis, Species, and Higher Taxa," 166). Boyd also claims (in apparent tension with his emphasis on property similarity in "Realism and Anti-Foundationalism") that the choice between labeling something a kind versus an individual is "merely pragmatic" (see "Homeostasis, Species, and Higher Taxa," 163) because both accommodate inferential practices. 
the most—or the most "causally basic" ${ }^{\prime 6}$ — properties of the cluster. In contrast, by identifying womanhood with historical properties, historical essentialism does not provide a standard of occurrent behavior or social positioning that individuals must approximate in order to achieve authentic status as a woman.

It is important to recall that while both Boyd and Mallon reference gender neither provide a HPC account of gender. ${ }^{87}$ On the other hand, social objectivism is formulated specifically as a theory of gender. Below I compare Haslanger's social objectivist theory of gender with historical essentialism and further describe the historical essentialist answers to the Commonality and Representation Problems.

\section{B. Comparison between Historical Essentialism and Haslanger's \\ Social Objectivism}

1. Inseparability.-The inseparability problem results from what Spellman calls "pop-bead metaphysics"-the mistaken view that gender is a discrete component of an individual that gets added, like a bead on a string, to other discrete components such as race and class. The mistake is to think that social properties like race and gender have a simple, additive relationship rather than a more relationally complex, perhaps emergent, relationship. Haslanger addresses this problem by providing an abstract definition of women. The central concept of subordination is described generally enough so that it can take on a variety of forms as a result of further social variables. But the generality of the definition cuts in the other direction as well, for it does not provide any specific way to think about the relationship between gender and other social properties.

In contrast, the historical kind approach provides a theoretical framework for thinking about intersectionality. In addition to gender systems, there are, presumably, a range of other systems that define historical social roles, such as "California migrant worker" and "Oprah's book club member." One approach to intersectionality is to study the actual historical relationships between replicating systems. A second direction of research may involve examining the compatibility between different social, teleological norms. If individuals participate in many social lineages that resulted from selective processes, then they each acquire an assortment of teleological norms. The historical kind approach provides criteria for individuating these norms - a first step in the study of their interaction. A third method

86. Robert A. Wilson, Matthew J. Barker, and Ingo Brigandt, "When Traditional Essentialism Fails: Biological Natural Kinds," Philosophical Topics 35 (2007): 189-215.

87. The absence of such an account also leaves the inseparability problem unresolved. Without an analysis of gender, we cannot evaluate the relationship between gender and other social kinds. 
is to examine nesting relationships that obtain between historical systems. Nested within the American gender system is the gender system at a university, and nested within the university gender system is the gender system of a fraternity. Empirical focus on the replicative relationships between nested systems, as well as the compatibility between their teleological norms, may reveal interesting facts about intersectionality.

2. Universality.-Individuals who are not subordinated on the basis of observed or imagined sex do not count as women on Haslanger's view. Mikkola questions whether this definition excludes the Queen of England. ${ }^{88}$ On the historical account, the only individuals who are not members of the kind women are those who have not undergone the ontogenetic processes through which one exemplifies a participatory relation to the historical gender role, and therefore other women. This means that women need not actually perform any aspect of their historical gender role. The queen is a woman if she has the right ontogeny, in which case she is supposed to be subordinated, but it is not essential to her womanhood that she actually is subordinated.

As discussed in Section V, women who do not participate in the same token gender system are not members of numerically the same historical gender kind. However, given the logical relationship between historical kind membership and possession of a teleological function, individuals with analogous historical gender roles are members of the same teleofunctional gender kind. If a token historical gender system were to have binary (or unary or ternary) gender roles that are not analogous to those of men and women, then individuals who occupy these roles would not be men or women. This is, I submit, a good result. Such individuals share neither history nor assigned social role, and so it is not clear what property, besides physiology, would justify their inclusion in the kinds men and women.

As discussed in Section V.D, the historical account excludes swamp-woman from the category women. If swamp-woman exhibits the surface indicators of womanhood, then others who are conditioned in a historical gender system are apt to systematically mistake "her" as a woman and treat her as if she were a woman (although if such treatment is prolonged it could eventually convert swamp-woman into a historical woman; see Sec. VI.B.3). While swamp-woman deserves moral consideration, her case does not undercut the historical basis of the political category women. In addition to recognizing morally relevant properties that swamp-woman shares with others (e.g., being conscious and self-aware), we can distinguish between what we can

88. Mari Mikkola, "Gender Concepts and Intuitions," Canadian Journal of Philosophy 39 (2009): 559-83, 565 . 
call "natural kind political representation" and "ad hoc political representation." The former advocates on behalf of categories for which members tend to share certain social and political properties (such as oppressions and opportunities) for the same reason. The latter advocates for individuals who accidentally share similarities with natural political kinds. While human flourishing and justice require both forms of representation, the need for ad hoc political representation should not serve as a corrective to natural kind political representation. To illustrate, suppose that a lightning storm strikes a bog and creates an individual who has the exact beliefs, desires, phenomenology, emotions, and memories as an actual holocaust survivor. "Swamp-holocaust survivor" (like swamp-woman) likely deserves some form of ad hoc political representation. Yet, I think most would agree that the existence of swamp-holocaust survivor should not cause us to change either the historical basis of the category holocaust survivor or the need for political advocacy specifically on behalf of holocaust survivors. Furthermore, I think most would agree that natural kind political representation has high practical importance because it locates natural social kinds with systematic, rather than accidental, sources of oppression. If a bizarre series of ecological and biochemical changes were to cause swamps everywhere to systematically produce swamp-women, then swamp-women would receive natural kind political representation as swamp-women. Otherwise, swamp-woman is represented ad hoc-not "as" a woman but "as if" a woman. ${ }^{89}$

3. Immutability.-Suppose that a patriarchal gender system underwent a gradual process of social change in which the gender role of women evolved to feature traditional masculine properties and social privilege and the gender role of men evolved to feature traditional feminine properties and social subordination. On Haslanger's view, it would seem to follow that females are now men and males are now women. Or suppose that the current gender system evolved into an egalitarian gender system. According to Haslanger's social objectivism, if individuals were neither subordinated nor privileged on the basis of sex, then "men" and "women" would be eliminated (though perhaps distinct gender groups would take their place).$^{90}$

These unintuitive results do not follow on the historical account of gender. So long as there are unfractured lineages that connect

89. Even if certain historical women (e.g., the Queen of England) or historical holocaust survivors fail to manifest properties that others might perceive as morally urgent (lack of opportunities, trauma, unpaid restitution, etc.), I contend that it is nonetheless important that they are morally and politically recognized as women and as holocaust survivors rather than recognized and represented ad hoc.

90. See Haslanger, "Gender and Race," 49-50. 
gender role occupants, then men and women retain their kind identity despite changes in the characteristic properties of their gender roles. Such lineages would also retain status as explanatory kinds in two respects. First, theoretical categories often accommodate scientific explanatory practices because they are inclusive of continuous historical stages and regardless of property dissimilarity between stages. After periods of substantial social change, it is likely that the historically defined categories men and women will continue to support social scientific explanatory practices, analogous to the way that categories for viruses, genes, meteorological events, and homologous traits continue to accommodate scientific explanatory practices across periods of property change. ${ }^{91}$ Second, changes to the characteristic properties of a gender role occur through a uniform and gradual process. ${ }^{92}$ At a particular time, then, it is still the case that kind members share likenesses which are grounded by historical processes. Now, if there were no longer a system of social interdependencies organized around bodily dimorphism, then historical gender roles, as well as men and women, would be eliminated. But given the social importance attributed to human reproduction and sexual difference, this is empirically unlikely. ${ }^{93}$ The compatibility between the historical account of gender and social change has important political implications. On the view that gender is a natural kind with a historical essence, it is possible for women of the present to pursue political causes that have the goal of eradicating oppression for women of the future. This is not possible on Haslanger's model of social objectivism.

A distinct form of mutability involves the changing gender status of a single individual. As Stone points out, Haslanger's view suggests that women who challenge their subordination are at the same time challenging their womanhood. ${ }^{94}$ Certainly the view implies that a woman who enters a position in which she is no longer subordinated thereby exits the category of women. Historical essentialism does not have this result. One's status as a woman is secured through events that occurred primarily before the age of ten. Thus gendered indi-

91. For example, Hull remarks: "Genes can belong to the same lineage even though they are structurally different from other genes in that lineage. What is more, continued changes in structure can take place indefinitely" (David Hull, "A Matter of Individuality," Philosophy of Science 45 [1978]: 335-60, 340).

92. Oriel Sullivan, Changing Gender Relations, Changing Families: Tracing the Pace of Change over Time (Lanham, MD: Rowman \& Littlefield, 2006).

93. Alcoff, "Visible Identities"; Marilyn Frye, "The Necessity of Differences: Constructing a Positive Category of Women," Signs 21 (1996): 991-1010.

94. Alison Stone, An Introduction to Feminist Philosophy (Cambridge: Polity Press, 2007). 
viduals can change in myriad ways while not affecting the relational property that is constitutive of their membership in a gender kind.

Because one's status as a man or woman is conditional upon historical relata, individuals cannot simply stipulate their gender status as "woman" or "man." Indeed, individuals do not have privileged access to historical processes, and it follows that they can be mistaken about their own gender status (it is less likely that they are mistaken about their gender identity).$^{95}$ Yet we should not infer from this that individuals have no control over their gender status. It may be arbitrary to restrict the ontogenetic processes that confer gender status to specific periods of development. If so, then individuals can be made reproductions of women or men in middle adulthood, say, as well as early childhood. It may be reasonable to interpret some transgender and transsexual individuals as initiating those ontogenetic processes that transform individuals into reproductions of whichever gender lineage they were not originally assigned. If a gender system directs its replicative machinery toward individuals on the basis of their appearance as male/man or female/woman, then one would need to present the right appearance in order to trigger the reproductive processes that confer membership to the desired gender lineage.

But at what point does an individual successfully transition into a new gender? During transition, is one a member of both genders at the same time? These are difficult questions, and they do not have clear answers. The empirical processes that ground kind membership for historical kinds are often uneven and "catch up some members more squarely than others." ${ }^{96}$ In these cases, the resulting historical kind will have vague boundaries. Compare this to eternal kinds, which tend to have sharp boundaries due to steady grounding principles such as microstructure. Transitions between historical kinds are also vague. As distinct ontogenetic processes displace older ones, there may be no precise moment at which an individual transitions from one gender to another. ${ }^{97}$ This is not unique to gender but rather generalizes to other historical kinds. For example, if a coffeehouse chain recycles its paper cups directly into paper napkins, there may be no precise moment at which the paper pulp transitions from one

95. Analogously, semantic externalists claim that the contents of many terms and concepts are determined by causal and/or historical relations between thinkers and world-relations which thinkers can be mistaken about (see, e.g., Hillary Putnam, "The Meaning of 'Meaning'," Minnesota Studies in the Philosophy of Science 7 [1975]: 215-71; Millikan, Language, Thought, and Other Biological Categories, and Clear and Confused).

96. Millikan, Clear and Confused, 25.

97. I will leave open the possibility that an individual can participate simultaneously in multiple gender lineages and possess multiple gender teleological functions. 
artifact kind to another. Recognition of vague transitions and vague borders results from the commitment to empirical, as opposed to conceptual, standards for classification.

4. Normativity.-The normativity problem is twofold. First, it states that any proposed definition of gender will entail that these experiences rather than those experiences are what count toward inclusion in a gender kind, thereby marginalizing individuals with experiences in the latter category. Haslanger, recall, treats this issue by falling back on the ameliorative aspect of her project. She concedes that her definition may marginalize nonsubordinated females, but relative to the general aims of feminist theory, "they are not the ones who matter." The second version of the normativity problem is that any definition of gender will end up having a normative effect. The specific concern for an account like Haslanger's is that individuals who strive to actualize their womanhood are striving for subordination. While Haslanger states that "[her] definition is more likely to offer a negative ideal that challenges male dominance," we are not given any reasons to hold this claim true. ${ }^{99}$

The historical essentialist response just given to the universality and immutability problems indicates a solution to the normativity problem. The historical view of gender is more inclusive than rival accounts of gender, and as a result it will marginalize fewer individuals. Marginalized individuals would be those who were not socialized as men or women. But these ontogenetic processes are ubiquitouscertainly more so than any of the properties described in the content of historical gender roles (properties that secure gender membership on other accounts). Nor does the historical account have trouble with the second normativity problem. Because it is one's ontogenetic history rather than one's psychology or social position that confers gender status, there are no current behaviors or social positions that one ought to pursue in order to actualize gender status.

5. The Representation Problem.-Nominalists about gender address the Commonality Problems by avoiding them: concerns about universality and normativity do not arise if there are no membership conditions for the kinds men and women. This tactic creates the Representation Problem: denying the existence of women as a group undercuts women's advocacy. The primary appeal of social objectivism is its capacity to theorize women as a real, mind-independent group while not invoking the strong universalism implicit in traditional ontologies of gender. The resource that enables this balancing act is the ontological notion of an objective type.

98. Haslanger, "Gender and Race," 46.

99. Ibid. 
An objective type is a mind-independent similarity class. As noted in Section III, this ontological classification is rather nondiscriminating. Objective types include "items on a desk," "items outside the moon's orbit," and "all the atoms that are not presently in the Queen of England's left thumb nail." In addition to being nondiscriminatory, objective types are nonexplanatory: claiming that a group of items is an objective type is to state a unity rather than explain a unity. In contrast, an ontology of historical kinds provides explanations for objective similarities. The present proposal agrees with Haslanger's social objectivism that women generally share the objective similarity of social subordination. But rather than making this property definitive of women, it explains this property as one of several properties that reliably co-occur as a result of a more fundamental, historical property.

\section{CONCLUSION}

According to historical essentialism, men form a natural kind and women form a natural kind. The essential property of women, in virtue of which an individual is a member of the kind "women," is participation in a lineage of women. In order to exemplify this relational property, an individual must be a reproduction of ancestral women, in which case she must have undergone the ontogenetic processes through which a historical gender system replicates women. As a result of her ontogenetic history, and also the phylogenetic history of women's gender role, a woman acquires a teleological gender function. Women from historically isolated cultures are members of the same teleofunctional gender kind and have the same teleofunctional gender norms if their historical gender roles are structurally analogous, that is, if they share the same type of ontogenetic history and their gender systems share the same type of phylogenetic history.

Most current accounts of gender ascribe weak ontological unities to gender kinds in order to avoid a set of problems associated with commonality, normativity, and political representation. These accounts mistake characteristic, objective similarities as definitive properties of a gender kind. While the resulting theories of gender may blunt the force of the above problems, they fail to eradicate them. The current essay has argued for the ironic conclusion that the Commonality and Representation Problems are best solved by offering a stronger ontological characterization-one that explains objective similarities in reference to an essential, historical property. I argued that replicative processes that take place during an individual's ontogenetic history cause an individual to participate in a historical gender lineage and that this replicative process explains why gendered 
individuals tend to share certain behavioral, psychological, and social properties. But by locating the essence of gender kinds in wider historical processes, the account allows for individuals who fail to exemplify characteristic gender properties to retain their gender status nonetheless. The account also provides strong grounds for a future, egalitarian gender system as compatible with the current, historically defined genders men and women. Finally, because these ontological claims are consistent with the classificatory practices employed in the natural and social sciences, they should not be reproached as post hoc solutions to the problem of political representation for gender categories. 